Economia e Sociedade, Campinas, Unicamp. IE. http://dx.doi.org/10.1590/1982-3533.2015v24n1 art6

\title{
Desempenho da indústria automobilística brasileira no período 2000-2012: uma análise sobre a hipótese de desindustrialização setorial *
}

\author{
Michele Polline Veríssimo \\ Vanessa Marzano Araújo ***
}

\begin{abstract}
Resumo
Este artigo investiga a possibilidade de desindustrialização na indústria automobilística brasileira. Parte-se da hipótese de que o contexto de taxa de câmbio apreciada e de altos preços das commodities pode inibir o desempenho da indústria automobilística no longo prazo. Ademais, busca-se captar os efeitos de taxa de investimento, juros, produtividade, impostos e abertura comercial sobre a produção de automóveis. Para isso, foram utilizadas a análise de Cointegração (Johansen Teste) e a estimação de Modelos de Vetores de Correção de Erros (VEC), com base no período 2000-2012. Os resultados sugerem efeitos positivos da apreciação cambial e dos preços das commodities sobre a produção de automóveis no longo prazo, o que não permite afirmar a ocorrência de desindustrialização no setor pela Doença Holandesa. Todavia, verifica-se a relevância de alta taxa de investimento, taxa de juros baixa, maior grau de abertura comercial, maior produtividade do trabalho e impostos menores para estimular a produção de automóveis no Brasil.
\end{abstract}

Palavras-chave: Desindustrialização; Indústria automobilística; Cointegração; VEC; Brasil.

\section{Abstract \\ Brazilian automotive industry performance in the period 2000-2012: an analysis of the deindustrialisation sector hypothesis}

This paper investigates the possibility of deindustrialization in the Brazilian automotive industry. It supposes that exchange rate appreciation and high commodity prices may inhibit the long run automotive industry performance. It also seeks to capture the effects of investment rate, interest rate, productivity, taxes and trade liberalization on car production. To do this, we used Cointegration analysis (Johansen Test) and Vector Error Correction Models (VEC), based on the period 2000-2012. The results suggest positive effects of currency appreciation and commodity prices on car production in the long run, which does not make it possible to confirm the existence of deindustrialization in the sector as a result of Dutch Disease. However, a high investment rate, low interest rate, higher trade openness, higher labor productivity and lower taxes are relevant in terms of stimulating car production in Brazil.

Keywords: Deindustrialization; Automotive industry; Cointegration; VEC; Brazil. JEL L16, L62, O14.

\footnotetext{
* Trabalho recebido em 14 de setembro de 2013 e aprovado em 8 de dezembro de 2014. As autoras agradecem o apoio financeiro recebido da Pró-Reitoria de Pesquisa e Pós-Graduação da Universidade Federal de Uberlândia (PROPP-UFU) para a realização da pesquisa.

*** Professora do Instituto de Economia da Universidade Federal de Uberlândia (IEUFU), Uberlândia, MG, Brasil. Email: michele@ie.ufu.br.

**** Professora da Universidade Federal de Goiás (UFG), Regional Catalão, Catalão, GO, Brasil. Email: vanessamarzano@gmail.com.
} 


\section{Introdução}

A economia brasileira foi caracterizada pela obtenção de baixas taxas de crescimento do Produto Interno Bruto (PIB) no período 2000-2012, em média, 3,4\% a.a., de acordo com os dados do Instituto Brasileiro de Geografia e Estatística (IBGE, 2013), especialmente quando comparadas ao conjunto das demais economias emergentes que formam o chamado BRICS (Rússia, Índia, China e África do Sul). As autoridades econômicas justificam o fraco desempenho da economia no período pós-2008 como decorrência dos efeitos da crise financeira internacional (sub-prime), porém, diversos analistas ressaltam a importância dos fatores internos, uma vez que o baixo crescimento do produto se assenta em questões estruturais que estão atreladas ao fraco dinamismo do setor industrial no país.

A teoria econômica, com base em Kaldor (1966), enfatiza que a atividade industrial é a maior responsável pelo crescimento das economias, na medida em que tal setor possui retornos crescentes de escala na produção, fortes efeitos de encadeamento para frente e para trás na cadeia produtiva, efeitos de aprendizado e de difusão de progresso tecnológico, além de possuir maior elasticidade-renda de importações do que os produtos primários, permitindo o relaxamento da restrição externa ao crescimento de longo prazo. Desta forma, este setor se mostra mais competitivo do que os setores baseados em recursos naturais, e é capaz de produzir efeitos multiplicadores mais expressivos sobre os resultados macroeconômicos (produto, emprego e renda) dos países.

Embora a indústria tenha um papel primordial para a alavancagem do produto, o que se percebe, no âmbito da experiência brasileira, é uma menor participação relativa da atividade industrial na geração de produto ao longo dos anos 2000, haja vista que, conforme os dados do IBGE (2013), a participação do valor adicionado da indústria no PÌB era de 27,3\% em 2000, caindo para 24,1\% em 2012. Este fato pode estar associado à relativa especialização da estrutura produtiva e exportadora da economia em bens intensivos em recursos naturais, nos quais o país conta com vantagens comparativas no comércio internacional, em meio a um cenário de elevação dos preços internacionais daqueles bens e de demanda externa favorável, dada, principalmente, pelo crescimento da economia chinesa, que se tornou a principal compradora deste tipo de produto no mercado exterior.

Este contexto tem ensejado uma preocupação com a possibilidade de ocorrência de Doença Holandesa e de desindustrialização na economia brasileira. Em outros termos, na medida em que a economia passa a exportar mais bens intensivos em recursos naturais, tem-se um processo de apreciação cambial que impossibilita a obtenção de uma rentabilidade adequada dos produtores nacionais 
de bens manufaturados. Como consequência, a indústria perde espaço na geração de produto e emprego. Considerando que a atividade industrial tem maiores efeitos de aprendizado e externalidades positivas com os demais setores da economia, a sustentabilidade da taxa de crescimento econômico em patamares adequados fica dificultada em uma perspectiva de longo prazo pelo baixo dinamismo da atividade industrial.

Para contenção dos efeitos da crise financeira internacional sobre a economia pós-2008, as autoridades governamentais brasileiras adotaram diversas medidas de estímulo à demanda agregada, especialmente pela via do consumo, utilizando instrumentos fiscais, como a redução ou isenção de IPI (Imposto sobre Produtos Industrializados) para a indústria automobilística e também para a indústria da chamada "linha branca". Embora tal esforço não fosse suficiente, o governo procurou eleger setores-chave da economia que detinham maiores capacidades de multiplicação de seus resultados. Foi o caso da indústria automobilística, reconhecida pela capacidade de geração de renda, de criação de empregos diretos e indiretos, e de fomento a várias outras indústrias na medida em que utiliza seus insumos.

Partindo dessa discussão inicial, este artigo tem como objetivo analisar os principais fatores que explicam o desempenho da indústria automobilística brasileira no período 2000-2012. Em outras palavras, o problema consiste em investigar o papel das variáveis cambial, fiscal, monetária e comercial para a explicação dos resultados da indústria automobilística. A hipótese preliminar deste trabalho se assenta no argumento de que o contexto de apreciação cambial verificado no decorrer da década de 2000, juntamente com uma situação externa favorável aos produtos primários (preços internacionais elevados), pode ser adverso ao desempenho do setor automotivo. Nestes termos, seria possível verificar alguns sinais de uma possível desindustrialização relativa no referido setor pela via da Doença Holandesa.

Cabe justificar que a análise sobre desindustrialização, no que tange à atividade automobilística, se encontra atrelada à suposição de que a ocorrência de Doença Holandesa e de desindustrialização pode envolver uma discussão setorial. Sendo assim, há que se verificar se os diversos setores da indústria de transformação brasileira estariam sofrendo os efeitos da apreciação cambial e dos altos preços das commodities de formas e intensidades diferentes. Dado a relevância atribuída à atividade automobilística no contexto recente da crise internacional, em função de seus efeitos multiplicadores de produto, emprego e renda, optou-se, neste trabalho, pela investigação do desempenho deste setor.

Para cumprir este propósito, será utilizada a metodologia de Cointegração (Teste de Johansen) e estimação do Modelo de Vetores de Correção de Erros 
(VEC) para avaliar os possíveis impactos (relações de longo prazo) de variáveis relacionadas às políticas fiscal (IPI), cambial (taxa de câmbio real), monetária (taxa de juros), industrial (taxa de investimento) e comercial (grau de abertura e preços das commodities) sobre a produção da indústria automobilística, com base no período 2000-2012.

Este trabalho se encontra estruturado em três seções, além desta introdução. A seção 1 apresenta sucintamente os fundamentos teóricos para balizar a discussão sobre a relevância da atividade industrial para os resultados econômicos e o papel do setor automobilístico. A seção 2 realiza uma análise descritiva do setor automobilístico nacional ao longo dos anos 2000. A seção 3 apresenta a metodologia para investigar alguns dos fatores explicativos da produção automobilística brasileira e discute os resultados obtidos. Por fim, são sistematizadas as principais conclusões do trabalho.

\section{Aspectos teóricos: indústria e crescimento econômico}

\subsection{A contribuição de Kaldor}

Este trabalho toma como pressuposto o papel da atividade industrial enquanto motor do crescimento econômico. Esta abordagem foi desenvolvida inicialmente por Kaldor (1966), que enfatiza a importância do padrão de especialização das economias para o crescimento, distinguindo as atividades com rendimentos crescentes (que ele associa à indústria) das atividades com rendimentos decrescentes (que ele associa à agricultura e mineração). Nestes termos, as economias baseadas na dinâmica da indústria de transformação obteriam uma taxa de crescimento econômico sustentada no longo prazo, pois este setor possui retornos crescentes de escala, influenciando o crescimento da produtividade de toda a economia. Por conseguinte, as diferenças das taxas de crescimento entre as economias capitalistas estariam relacionadas às diferentes estruturas produtivas que as caracterizam (Thirlwall, 2005).

Esta análise derivou um conjunto de leis, chamadas de Leis de Kaldor, que consistem nas seguintes proposições (Oreiro; Feijó, 2010; Lamonica; Feijó, 2011; Libânio, 2012):

i) Existe uma relação positiva entre o crescimento da indústria e o crescimento do produto agregado, assim, quanto maior a taxa de crescimento da indústria, maior será a taxa de crescimento do produto agregado.

ii) Há uma relação positiva entre a taxa de crescimento da produtividade na indústria e o crescimento do produto industrial, sendo que quanto maior a taxa de crescimento da indústria, maior será também a taxa de crescimento da produtividade. 
iii) Quanto maior a taxa de crescimento das exportações, maior o crescimento do produto.

iv) $\mathrm{O}$ crescimento da economia no longo prazo não é restringido pela oferta, mas sim pela demanda, desta forma, a principal restrição da demanda ao crescimento do produto em uma economia aberta é o Balanço de Pagamentos.

Neste sentido, uma das principais conclusões que Kaldor obtém é a de que as exportações, principalmente de produtos industrializados, são essenciais para o dinamismo das economias ao longo do tempo. A importância dada às exportações explica-se pelo fato desta ser um componente da demanda agregada que induz o crescimento do produto, além de gerar divisas (capacidade de importação), aliviando a restrição externa ao Balanço de Pagamentos.

Na interpretação de Kaldor, a expansão da atividade industrial aumenta a produtividade na indústria de transformação. Esta maior produtividade eleva a competitividade das exportações e estimulando seu aumento, provocando um aumento no produto. Este produto mais elevado, por sua vez, aumentaria as importações. Dessa forma, seria necessário que as exportações crescessem, no mínimo, ao mesmo ritmo das importações. Esse padrão de desenvolvimento econômico levaria a um processo cumulativo do crescimento em função dos retornos crescentes presentes na indústria de transformação.

Cabe destacar que, na visão de Kaldor, deve ser encorajada uma aceleração da taxa de crescimento das exportações para os setores nos quais a demanda mundial é crescente. Nestes termos, a especificação de um modelo de crescimento liderado pelas exportações (export-led growth) deve ser baseada nas exportações de produtos manufaturados, os quais têm retornos crescentes de escala, maior produtividade e efeitos de encadeamento com os demais setores da economia. De acordo com Lamonica e Feijó (2011), se a economia não atingiu ainda um nível de industrialização com tais características, as autoridades econômicas precisam incentivar mudanças estruturais para alcançar um padrão de desenvolvimento focado nas indústrias com retornos de escala crescentes, notadamente, as que produzem bens com maior conteúdo tecnológico e valor agregado.

Em linha com tal argumento, trabalhos como os de Dalum, Laursen e Verspagen (1996), Haussman et al. (2005) e Rodrik (2006) partem do pressuposto de que países especializados nas exportações de produtos com tecnologia sofisticada apresentam patamares mais elevados de crescimento econômico, dado o potencial dinâmico de criação e difusão das inovações e ganhos de produtividade derivados da indústria. Neste sentido, os países não devem se preocupar apenas com o volume das exportações, mas também com o perfil 
daquilo que é exportado, se as mesmas desejam obter taxas de crescimento econômico mais sustentadas ao longo do tempo. Deste modo, as economias devem estimular uma mudança do padrão de especialização das estruturas produtivas e exportadoras na direção de bens com conteúdo tecnológico mais sofisticado. Segundo Rodrik (2006), este teria sido o caso da economia chinesa, cujo excepcional ritmo de crescimento encontra-se relacionado não só ao aumento das exportações em decorrência das medidas de abertura comercial e de câmbio desvalorizado, mas também à mudança da composição das exportações em direção a uma cesta de produtos mais sofisticados do que aquela esperada para países de níveis de renda semelhantes.

\subsection{Desindustrialização}

Uma vez que a atividade industrial pode ser considerada como o motor do crescimento econômico, a ocorrência de um processo de desindustrialização implica na obtenção de baixas taxas de crescimento do produto para as economias ao longo do tempo.

O conceito original de desindustrialização está relacionado às alterações na estrutura produtiva, na medida em que ocorre um avanço da renda per capita nas economias. Nesta condição, haveria uma relação em forma de U entre especialização produtiva e renda per capita explicada pelo fato de que em estágios mais avançados do desenvolvimento econômico ocorre uma desaceleração do crescimento da demanda por bens manufaturados, ao passo que a produtividade na indústria continua crescendo, diminuindo a mão de obra empregada neste setor. Ademais, dada a maior elasticidade-renda dos serviços em relação aos bens industriais, a demanda por serviços passa a registrar forte incremento, enquanto a produtividade do setor terciário continua em expansão, embora em ritmo menor do que o da indústria, resultando em maior absorção de trabalhadores (Rowthorn; Ramaswamy, 1999).

Nas condições acima mencionadas, a desindustrialização é vista como um processo natural ao longo da trajetória de desenvolvimento dos países. No entanto, o problema que se apresenta é que algumas economias em desenvolvimento estariam incorrendo em um processo de especialização prematura, com uma perda de participação da indústria sem que esta tenha completado seu pleno processo de desenvolvimento, ou seja, em níveis de renda inferiores aos dos países desenvolvidos (Carvalho; Kupfer, 2007).

Algumas discussões sobre um eventual processo de desindustrialização na economia brasileira sugerem um movimento precoce de perda de participação da indústria doméstica no valor adicionado. Este movimento não seria consequência natural do desenvolvimento da economia em função de padrões 
mais elevados da renda per capita, mas sim resultado da perda de competitividade do setor industrial em um contexto de apreciação cambial que conduz à especialização da produção em setores de bens intensivos em recursos naturais, problema este denominado como "Doença Holandesa"1.

Tal definição de desindustrialização é fundamentada no modelo desenvolvido por Corden e Neary (1982) e aprimorado em Corden (1984). Este modelo especifica a existência de três setores: o setor em expansão (booming sector), o setor que cresce lentamente e o setor de bens não comercializáveis. A ampliação do setor em expansão (derivada de progresso técnico, da descoberta de recursos, ou de mudança nos preços) promove o aumento da renda dos fatores empregados no setor e acarreta dois efeitos. O primeiro é o "efeito de gastos", em que parte da renda extra do setor em expansão aumenta a demanda por bens não comercializáveis e eleva os preços destes bens em relação aos preços dos comercializáveis, apreciando a taxa real de câmbio. O segundo é o "efeito deslocamento dos recursos", em que a demanda por trabalho no setor em expansão aumenta a remuneração deste fator e provoca o deslocamento de recursos dos outros setores da economia para o setor em expansão, reduzindo a produção de bens comercializáveis e causando a desindustrialização.

Em uma extensão analítica do modelo original da Doença Holandesa, Bresser-Pereira e Marconi (2008) associam o setor de produtos comercializáveis que cresce rapidamente (booming sector) à extração de produtos naturais ou produção de grãos, em que o país possui vantagens comparativas, e o setor de bens comercializáveis que cresce mais lentamente é relacionado à indústria. Segundo os autores, o setor que produz recursos naturais tende a expandir rapidamente suas receitas de exportação, o que leva à apreciação cambial, e, em consequência, desestimula as exportações de manufaturados. Deste modo, uma parcela dos fatores produtivos é deslocada para os setores que produzem recursos naturais e bens não comercializáveis e pode acarretar a desindustrialização em função da queda das vendas externas de manufaturados e do aquecimento dos demais setores.

Bresser-Pereira (2009) desenvolve um modelo de Doença Holandesa, cuja base é a existência de rendas ricardianas que levam a uma distinção entre a taxa de câmbio de equilíbrio corrente $(\varepsilon c)$, que equilibra intertemporalmente a conta corrente de um país, e a taxa de câmbio de equilíbrio industrial (ci), que permite que as empresas que utilizam tecnologia sofisticada sejam rentáveis ou competitivas. De acordo com o modelo, se um país possui recursos naturais (e

(1) Essa denominação foi dada pela literatura econômica ao efeito negativo que a descoberta e o aumento das exportações de gás natural geraram sobre a taxa de câmbio real (apreciação) na Holanda nos anos 1960, prejudicando a produção industrial (desindustrialização) e acarretando baixas taxas de crescimento econômico naquele país. 
humanos) abundantes, a utilização desses recursos permite que os produtos sejam produzidos e exportados a custos menores do que os dos concorrentes internacionais, levando ao surgimento de rendas ricardianas. $\mathrm{O}$ baixo custo marginal dos produtos exportados possibilita que a taxa de câmbio corrente seja mantida artificialmente valorizada em relação à taxa de câmbio que tornaria os bens industriais - que o país produz com a mesma eficiência dos seus concorrentes - competitivos internacionalmente. Essa valorização cambial favorece a especialização do país em setores intensivos em recursos baratos dotados de vantagens comparativas, ao passo que desestimula a produção de setores que não possuem essas vantagens, tais como os bens manufaturados intensivos em tecnologia. Tal situação, dependendo da intensidade das rendas ricardianas e do grau de apreciação da moeda, pode ocasionar a desindustrialização e o baixo crescimento econômico no longo prazo.

Além da definição de desindustrialização ligada à Doença Holandesa, certos estudos avaliam o conceito de "desindustrialização induzido por políticas econômicas". Este conceito tem origem no trabalho de Palma (2005), que analisa a relação entre emprego industrial e renda per capita (curva do "U invertido") em diversas economias no pós-guerra.

Palma (2005) identifica quatro fontes de desindustrialização: i) relação de "U invertido" entre o emprego industrial e a renda per capita, com o declínio no emprego industrial quando os países atingem certo nível de renda per capita; ii) relação inversa entre renda per capita e emprego industrial para países de renda média e alta em decorrência das mudanças no paradigma tecnológico e da realocação de parte do processo produtivo (intensivo em mão de obra) para países em desenvolvimento; iii) queda no tempo da relação de "U invertido" para países de renda média e alta; e iv) Doença Holandesa, em que os países registram uma queda no emprego industrial maior do que aquela que seria esperada em função das três fontes de desindustrialização anteriores. Além disso, o autor sugere que a desindustrialização nos países latino-americanos se encontra relacionada às mudanças na política econômica, caracterizadas pela liberalização comercial e financeira nos anos 1990. Tais mudanças afetaram o nível industrial das economias na medida em que seus processos de industrialização deixaram de ser induzidos pela política de substituição de importações para retornar à posição ricardiana natural associada com vantagens comparativas de acordo com a abundância de recursos tradicionais.

\subsection{O papel da indústria automobilística para o crescimento econômico}

A evolução da indústria automobilística sempre esteve ligada ao desenvolvimento do próprio capitalismo. Foi responsável por trazer novas formas da organização do trabalho como, por exemplo, o fordismo, o toyotismo, a 
acumulação flexível, entre outros. Tais métodos de produção de bens também foram aplicados com sucesso em outras atividades industriais, constituindo-se em importantes inovações para as empresas. As empresas deste setor investem constantemente em Pesquisa e Desenvolvimento (P\&D) na busca por produtos cada vez mais sofisticados, com novo design, maior nível tecnológico, maior durabilidade, e também na busca por combustíveis alternativos. Além disso, as empresas montadoras de automóveis apresentam grande necessidade de se articular com outras empresas, tanto a jusante quanto a montante, estabelecendose em forma de redes. Portanto, são indústrias que atraem fabricantes de autopeças e também utilizam produtos de vários segmentos industriais em seu processo produtivo, por exemplo, vidro, aço, ferro, alumínio, plástico, tapetes, chips de computador, entre outros (Silva, 2010; Oica, 2013).

Também é preciso considerar que tais empresas movimentam uma grande quantidade de capital. E para obter lucro, necessitam apresentar volume de produção, obter fornecedores especializados e se relacionar com o mercado consumidor, muitas vezes intermediado pelas concessionárias. Sendo assim, os fluxos que entrelaçam as montadoras às demais empresas participantes da rede é grande. Geralmente, a jusante da cadeia estão os fornecedores de autopeças, prestadoras de serviços e empresas terceirizadas. A montante estão as concessionárias, transportadoras e os consumidores. Tudo isso forma fluxos materiais e imateriais em um emaranhado de relações em diversos lugares do país e até do exterior (Silva, 2010). Nestes termos, pode-se inferir que as empresas do setor automobilístico exercem efeitos multiplicadores sobre vários outros setores da economia, e são importantes como elementos geradores de emprego e renda, direta ou indiretamente. Daí a importância de se estimular o crescimento e o desenvolvimento deste setor, a fim de se sustentar a manutenção e a expansão da atividade econômica como um todo.

A indústria automobilística é um setor-chave para as principais economias do mundo, sendo responsável pela geração de cerca de 9 milhões de empregos diretos, o que representa cerca de 5\% do emprego mundial. Além disso, para cada emprego direto gerado, estima-se que mais de cinco empregos indiretos sejam criados. Este setor é capaz de gerar uma receita bruta de aproximadamente $€ 2$ trilhões, e contribui aos cofres públicos com o pagamento de impostos na soma de aproximadamente $€ 430$ bilhões (Oica, 2013).

Devido a sua importância, tal indústria vem ganhando destaque nos últimos anos na construção de políticas públicas, principalmente no Brasil, onde houve estímulo para desconcentração regional e redução de impostos. As políticas públicas de desconcentração regional se iniciaram em 1996 com o estabelecimento do "Regime Automotivo Regional ou Especial" (MP 1.532), e seu objetivo foi incentivar a instalação de montadoras nas regiões Norte, Nordeste 
e Centro-Oeste, com redução de impostos de importação de peças e componentes, isenção/redução de IPI (Imposto sobre Produtos Industrializados), IR (Imposto de Renda) e IOF (Imposto sobre Operações Financeiras) nas aquisições de matérias-primas e insumos, entre outros (Negri, 2013). Mais recentemente, em 2008/2009 e em 2012/2013, foram reduzidas as alíquotas do IPI de automóveis, desta vez com efeitos em todo o Brasil. A justificativa do governo para esse setor ser o primeiro a ser contemplado foi que ele tem grande capacidade de impactos multiplicadores tanto a jusante quanto a montante da cadeia produtiva. Portanto, pode gerar desdobramentos positivos sobre toda a economia. Depois também foram contemplados com a redução do imposto os materiais de construção e eletrodomésticos da linha branca. Os principais indicadores da indústria automobilística brasileira serão abordados na próxima seção.

\section{Indicadores da Indústria Automobilística Brasileira}

Nesta seção, serão mostrados dados que retratam a realidade da indústria automobilística no Brasil e de suas cinco regiões geográficas, incluindo aquela considerada o berço da indústria automobilística (região Sudeste) e as outras regiões estimuladas por incentivos fiscais.

Ao se analisar a produção industrial de um setor, um dos principais indicadores é o chamado Valor da Transformação Industrial (VTI). Tal indicador é importante por mostrar a repartição da renda industrial em determinado setor, nesse caso, da indústria automobilística.

A Tabela 1 apresenta a evolução do VTI da indústria automobilística no período 2000-2010. Os dados apontam um crescimento significativo e contínuo do valor da transformação do setor automobilístico nacional durante a década de 2000 e confirma que, apesar dos incentivos fiscais para o ramo automobilístico, a Região Sudeste continua sendo aquela em que se concentra a maior parte das empresas desse setor. Em termos comparativos, a análise do VTI médio alcançado para cada região durante a década de 2000 revela que a Região Sudeste representou cerca de $75 \%$ do VTI da fabricação e montagem de automóveis no país. A segunda região melhor colocada foi a região Sul, que representou $20 \%$ do VTI total do setor, sendo que este valor para as três regiões restantes em conjunto foi equivalente a apenas 4,5\% do VTI da indústria automobilística total. Destacase que, embora a Região Centro-Oeste tenha uma participação média baixa no VTI nacional do setor automobilístico $(0,9 \%)$, tal região contou com um significativo avanço na transformação de valor para a atividade automobilística na última década, passando de $\mathrm{R} \$ 19,64$ milhões em 2000 para $\mathrm{R} \$ 1,6$ bilhões em 2010 . 
Tabela 1

Valor da transformação industrial da fabricação e montagem de veículos automotores brasileira (em R \$ Bilhões e em \%) no período 2000-2010

\begin{tabular}{c|c|c|c|c|c|c|c|c|c|c|cc}
\hline & \multicolumn{2}{|c|}{ Sudeste } & \multicolumn{2}{c|}{ Sul } & \multicolumn{2}{c|}{ Centro-Oeste } & \multicolumn{2}{c|}{ Norte } & \multicolumn{2}{c|}{ Nordeste } & \multicolumn{3}{c}{ Brasil } \\
\hline & $\mathrm{R} \$$ & $\%$ & $\mathrm{R} \$$ & $\%$ & $\mathrm{R} \$$ & $\%$ & $\mathrm{R} \$$ & $\%$ & $\mathrm{R} \$$ & $\%$ & $\mathrm{R} \$$ & $\%$ \\
\hline 2000 & 14,18 & 80,2 & 3,37 & 19,1 & 0,02 & 0,1 & 0,03 & 0,2 & 0,07 & 0,4 & 17,67 & 100 \\
2001 & 15,04 & 79,0 & 3,87 & 20,3 & 0,03 & 0,1 & 0,05 & 0,2 & 0,05 & 0,3 & 19,03 & 100 \\
2002 & 17,85 & 75,4 & 4,97 & 21,0 & 0,09 & 0,4 & 0,13 & 0,5 & 0,64 & 2,7 & 23,68 & 100 \\
2003 & 22,91 & 75,1 & 6,31 & 20,7 & 0,15 & 0,5 & 0,12 & 0,4 & 1,03 & 3,4 & 30,52 & 100 \\
2004 & 27,95 & 75,3 & 7,58 & 20,4 & 0,25 & 0,7 & 0,12 & 0,3 & 1,23 & 3,3 & 37,14 & 100 \\
2005 & 29,93 & 75,9 & 7,47 & 18,9 & 0,39 & 1,0 & 0,07 & 0,2 & 1,60 & 4,1 & 39,46 & 100 \\
2006 & 33,44 & 75,4 & 8,41 & 19,0 & 0,44 & 1,0 & 0,08 & 0,2 & 1,96 & 4,4 & 44,34 & 100 \\
2007 & 38,78 & 74,9 & 10,24 & 19,8 & 0,72 & 1,4 & 0,08 & 0,2 & 1,95 & 3,8 & 51,77 & 100 \\
2008 & 51,02 & 72,6 & 14,34 & 20,4 & 0,97 & 1,4 & 0,29 & 0,4 & 3,66 & 5,2 & 70,28 & 100 \\
2009 & 48,29 & 71,8 & 14,60 & 21,7 & 1,14 & 1,7 & 0,19 & 0,3 & 3,06 & 4,5 & 67,28 & 100 \\
2010 & 60,79 & 73,2 & 16,93 & 20,4 & 1,66 & 2,0 & 0,18 & 0,2 & 3,54 & 4,3 & 83,09 & 100 \\
\hline Média & 32,74 & 75,3 & 8,92 & 20,1 & 0,53 & 0,9 & 0,12 & 0,3 & 1,71 & 3,3 & 44,02 & 100 \\
\hline
\end{tabular}

Fonte: Elaboração própria com os dados da PIA - IBGE.

A Tabela 2 mostra o número total de empresas que fizeram parte da indústria automobilística brasileira no período 2000-2010. É possível perceber que houve um aumento importante do número total de empresas no setor $(11,5 \%)$ no período considerado.

Os dados indicam que a rede que envolve o setor automobilístico no Brasil abrange uma participação muito significativa de micro e pequenas empresas, em média, $90 \%$ do total. No entanto, houve oscilação em termos do porte das empresas inseridas no setor entre 2000 e 2010. As microempresas tiveram uma perda de participação de 11 p.p., enquanto as empresas de pequeno porte brasileiras ganharam participação de 7,3 p.p. no período. As empresas de médio e grande porte ganharam participação de 2,0 p.p. e de 1,6 p.p., respectivamente, durante a década analisada. É preciso ressaltar que o número total de grandes empresas da indústria automobilística brasileira praticamente dobrou em dez anos (Tabela 2), isso demonstra um resultado positivo, uma vez que mais de $70 \%$ da mão de obra empregada no setor presta serviço em empresas de grande porte, conforme demonstra a Tabela 3, na sequência. 
Tabela 2

Total de empresas por porte na indústria automobilística brasileira no período 2000-2010

\begin{tabular}{c|c|c|c|c|c|c|c|c|c|c}
\hline & Micro & $\%$ & Pequena & $\%$ & Média & $\%$ & Grande & $\%$ & Total & $\%$ \\
\hline 2000 & 4.068 & 69,1 & 1.309 & 22,5 & 359 & 6,1 & 148 & 2,5 & 5.884 & 100 \\
2001 & 4.217 & 69,0 & 1.366 & 22,4 & 380 & 6,2 & 146 & 2,4 & 6.109 & 100 \\
2002 & 4.235 & 68,4 & 1.433 & 23,1 & 377 & 6,1 & 146 & 2,4 & 6.191 & 100 \\
2003 & 4.148 & 67,0 & 1.466 & 23,7 & 410 & 6,6 & 168 & 2,7 & 6.192 & 100 \\
2004 & 4.127 & 65,2 & 1.561 & 24,7 & 453 & 7,2 & 189 & 3,0 & 6.330 & 100 \\
2005 & 4.229 & 65,1 & 1.603 & 24,7 & 457 & 7,0 & 206 & 3,2 & 6.495 & 100 \\
2006 & 4.007 & 62,6 & 1.728 & 27,0 & 467 & 7,3 & 199 & 3,1 & 6.401 & 100 \\
2007 & 3.372 & 56,6 & 1.841 & 30,9 & 519 & 8,7 & 226 & 3,8 & 5.958 & 100 \\
2008 & 3.626 & 57,0 & 1.933 & 30,4 & 543 & 8,5 & 256 & 4,0 & 6.358 & 100 \\
2009 & 3.723 & 57,4 & 1.942 & 29,9 & 560 & 8,6 & 259 & 4,0 & 6.484 & 100 \\
2010 & 3.816 & 58,2 & 1.937 & 29,5 & 534 & 8,1 & 272 & 4,2 & 6.559 & 100 \\
\hline
\end{tabular}

Fonte: Elaboração própria com os dados do CEMPRE - IBGE.

A Tabela 3 mostra o pessoal ocupado na indústria automobilística brasileira no período 2000-2010. Verifica-se que a indústria automobilística contou com um aumento de 75,4\% no número de empregos entre 2000 e 2010. Daí a importância deste setor na geração de emprego e renda para a economia. As empresas de grande porte foram as maiores responsáveis pela geração de empregos no setor, representando, em média, 74\% do total de empregos. Este tipo de empresa teve um ganho de 5,8 p.p. de participação no emprego total na atividade. Em seguida, aparecem as empresas de médio porte, com $13 \%$ do total de empregos no setor. Há que se destacar que as pequenas e microempresas tiveram uma participação menor no emprego, em média, 9,3\% e 3,3\%, respectivamente, e perderam participação (1,8 p.p. e 1,7 p.p., respectivamente) na geração de empregos na atividade no período analisado.

Tabela 3

Pessoal Ocupado por Porte na Indústria Automobilística Brasileira (em Número de Pessoas e em \%) no Período 2000-2010

\begin{tabular}{c|c|c|c|c|c|c|c|c|c|c}
\hline & Micro & $\%$ & Pequena & $\%$ & Média & $\%$ & Grande & $\%$ & Total & $\%$ \\
\hline 2000 & 11.727 & 4,3 & 27.976 & 10,0 & 38.900 & 13,9 & 200.982 & 71,9 & 279.585 & 100 \\
2001 & 11.885 & 4,2 & 29.048 & 10,3 & 40.950 & 14,6 & 199.040 & 70,8 & 280.923 & 100 \\
2002 & 12.156 & 4,3 & 30.501 & 10,8 & 40.399 & 14,3 & 200.089 & 70,7 & 283.145 & 100 \\
2003 & 11.870 & 3,8 & 30.934 & 10,0 & 43.152 & 13,9 & 224.403 & 72,3 & 310.359 & 100 \\
2004 & 11.809 & 3,2 & 32.474 & 8,9 & 48.257 & 13,2 & 272.195 & 74,6 & 364.735 & 100 \\
2005 & 12.121 & 3,3 & 33.593 & 9,2 & 47.334 & 12,9 & 273.875 & 74,6 & 366.923 & 100 \\
2006 & 11.917 & 3,1 & 35.576 & 9,3 & 49.210 & 12,8 & 287.452 & 74,8 & 384.155 & 100 \\
2007 & 11.387 & 2,7 & 38.412 & 9,1 & 55.067 & 13,1 & 315.449 & 75,0 & 420.315 & 100 \\
2008 & 11.639 & 2,4 & 40.717 & 8,5 & 57.512 & 12,0 & 369.232 & 77,1 & 479.100 & 100 \\
2009 & 12.677 & 2,6 & 41.521 & 8,5 & 58.816 & 12,0 & 377.554 & 77,0 & 490.568 & 100 \\
2010 & 12.984 & 2,6 & 40.328 & 8,2 & 56.003 & 11,4 & 381.167 & 77,7 & 490.482 & 100 \\
\hline
\end{tabular}

Fonte: Elaboração própria com os dados do CEMPRE - IBGE 
A Tabela 4 apresenta os resultados salariais obtidos pelo setor automobilístico no período $2000-2010^{2}$. Os dados revelam a importância da manutenção do ritmo da atividade automobilística pelos efeitos multiplicadores de renda que a mesma pode exercer. Os níveis salariais médios pagos no setor são bastante expressivos, sendo que os valores pagos em média no país praticamente duplicaram entre 2000 e 2010.

Nestes termos, verifica-se que a prioridade do governo em manter os empregos e os salários na atividade automobilística foi relevante como elemento sustentador da demanda agregada, principalmente dado o peso da atividade na geração de renda na região Sudeste, que é o centro econômico do país, seguido pelas regiões Sul e Nordeste. Cabe salientar que a região Centro-Oeste foi a que pagou os menores salários anuais médios para os trabalhadores do setor. Em 2010, os rendimentos recebidos pelos trabalhadores que prestaram serviço na região Centro-Oeste foram cerca de $53 \%$ dos recebidos por seus pares na região Sudeste.

Tabela 4

Salário Anual Médio na Indústria Automobilística no Período 2000-2010

$(\mathrm{R} \$ \mathrm{Mil}) *$

\begin{tabular}{cccccccc}
\hline Ano & Sudeste & Sul & Nordeste & Centro-Oeste & Brasil \\
\hline 2000 & 21,58 & 15,77 & 7,91 & 4,58 & 19,95 \\
2001 & 23,77 & 16,55 & 6,94 & 5,59 & 21,72 \\
2002 & 24,08 & 19,72 & 13,39 & 7,32 & 22,64 \\
2003 & 26,95 & 21,93 & 17,60 & 10,47 & 25,42 \\
2004 & 27,92 & 23,30 & 14,01 & 12,21 & 26,20 \\
2005 & 30,09 & 24,87 & 15,78 & 15,28 & 28,32 \\
2006 & 32,34 & 26,23 & 19,65 & 23,12 & 30,38 \\
2007 & 33,14 & 27,55 & 33,49 & 16,16 & 31,49 \\
2008 & 36,61 & 28,01 & 26,73 & 21,50 & 34,08 \\
2009 & 37,51 & 28,46 & 33,16 & 20,90 & 34,99 \\
2010 & 40,21 & 30,25 & 24,77 & 21,31 & 37,18 \\
\hline
\end{tabular}

* Pessoal Ocupado em 31/12

Fonte: Elaboração própria com os dados da PIA - IBGE

A Tabela 5 mostra os valores anuais que foram arrecadados pelo governo com IPI para a indústria de transformação e automobilística no período 20002012.

Observa-se que a arrecadação anual de IPI de automóveis aumentou 75\% no período e representou, em média, $13 \%$ da arrecadação de IPI com a indústria

(2) O salário anual médio pode ser calculado por meio da relação entre o Salário Anual (SA) e o Pessoal Ocupado (PO), ou seja: SA/PO. 
de transformação. Destaca-se que, em 2009 e em 2012, houve grande queda na arrecadação de IPI dos automóveis. Nesses anos, a arrecadação da indústria automobilística representou cerca de $7 \%$ e $9 \%$, respectivamente, da receita de IPI arrecadada pela indústria de transformação. Isso ocorreu porque o governo federal decretou isenção e/ou redução na alíquota para alguns veículos e caminhões. Com tais medidas, o governo brasileiro objetivou reduzir os impactos da crise econômica mundial no consumo doméstico ao estimular as vendas da indústria automobilística, e, consequentemente, manter os empregos e a renda obtida pelos trabalhadores do setor para sustentar a demanda em outros setores da economia nacional.

Tabela 5

Arrecadação do Imposto sobre Produtos Industrializados (IPI) no Período 2000-2012

(Receita Bruta em R\$ Milhões)

\begin{tabular}{l|cc|c}
\hline & Automóveis & Indústria de Transformação & $\%$ \\
\hline 2000 & $2.374,81$ & $18.839,05$ & 12,6 \\
2001 & $2.594,65$ & $19.455,74$ & 13,3 \\
2002 & $2.663,94$ & $19.798,10$ & 13,5 \\
2003 & $2.313,57$ & $19.674,25$ & 11,8 \\
2004 & $2.964,89$ & $22.910,41$ & 12,9 \\
2005 & $3.733,06$ & $26.380,72$ & 14,2 \\
2006 & $4.289,88$ & $28.159,58$ & 15,2 \\
2007 & $5.244,57$ & $34.063,09$ & 15,4 \\
2008 & $5.997,96$ & $39.466,08$ & 15,2 \\
2009 & $2.053,69$ & $30.752,59$ & 6,7 \\
2010 & $5.672,02$ & $39.990,51$ & 14,3 \\
2011 & $6.977,99$ & $46.917,87$ & 14,9 \\
2012 & $4.125,78$ & $45.927,42$ & 9,0 \\
\hline
\end{tabular}

Fonte: Elaboração própria com os dados do Ipeadata.

Na sequência, o foco de análise recai sobre a análise dos fatores explicativos da produção da indústria automobilística brasileira, apresentando o modelo empírico de análise.

\section{Determinantes da produção da indústria automobilística brasileira no Período 2000-2012}

\subsection{Metodologia}

O presente trabalho se propõe a investigar os efeitos das condições macroeconômicas no âmbito cambial (taxa de câmbio real), fiscal (arrecadação de IPI), monetário (taxa de juros), industrial (taxa de investimento) e comercial (grau de abertura) em conjunto com a especialização da economia em bens 
intensivos em recursos naturais (preços das commodities) sobre o desempenho da produção da indústria de veículos automotores brasileira.

O intuito desta análise consiste em investigar a existência de sinais de desindustrialização em um setor específico da indústria de transformação brasileira - o automobilístico - pela via da Doença Holandesa (efeitos da apreciação cambial e dos preços internacionais das commodities), tomando-se como base o período 2000-2012. Ademais, pretende-se avaliar os impactos de medidas adotadas pelas autoridades governamentais a fim de estimular a demanda interna em termos da redução/isenção de impostos sobre o setor (IPI) e de medidas estruturais, como o grau de abertura comercial, a taxa de juros e a taxa de investimento da economia. Parte-se da hipótese preliminar de que a apreciação cambial e os altos preços das commodities podem exercer um impacto negativo sobre o desempenho da indústria brasileira, mas as reduções de impostos e da taxa de juros, os ganhos de produtividade da força de trabalho e uma taxa de investimento mais elevada se mostram importantes para alavancar a produção industrial.

Para a análise desses efeitos, este trabalho utiliza a metodologia de Cointegração e estimação do Modelo de Vetores de Correção de Erros (VEC). Dado duas ou mais séries temporais não estacionárias, se o resíduo da combinação linear entre elas for estacionário, pode-se dizer que tais séries são cointegradas. Tal fato acontece porque a combinação linear entre séries não estacionárias faz com que as tendências estocásticas das séries se anulem entre si (GUJARATI, 2006). Nestes termos, segundo os pressupostos de Engle e Granger (1987), os elementos do vetor Xt, n x 1, são ditos cointegrados de ordem (d, b), denotados por $\mathrm{Xt} \sim \mathrm{CI}(\mathrm{d}, \mathrm{b})$, se:

i) Todos os elementos de Xt são integrados de ordem d, ou seja, são $\mathrm{I}(\mathrm{d})$.

ii) Existe um vetor não nulo, $\beta$, tal que ut $=\mathrm{Xt}^{\prime} \beta \sim \mathrm{I}(\mathrm{d}, \mathrm{b}), \mathrm{b}>0$.

Do ponto de vista econômico, duas variáveis serão cointegradas se tiverem uma relação de longo prazo ou de equilíbrio entre elas. Formalmente, diz-se que existe um equilíbrio de longo prazo quando $\mathrm{Xt}^{\prime} \beta=0$, isto é, o vetor $\beta$, chamado vetor de cointegração, define uma combinação linear perfeita entre os elementos de Xt no sentido de seguir uma tendência em comum, sem desvio (Bueno, 2008, p. 204).

No curto prazo, podem ocorrer desvios dessa tendência comum, de modo que o erro de equilíbrio (ut) expressa os desvios temporários do equilíbrio de longo prazo entre as séries analisadas. Nestas condições, a relação de longo prazo é perturbada por choques de curto prazo representados por ut, porém, sendo este termo estacionário, tais perturbações serão dissipadas ao longo do tempo. O 
tempo necessário para a dissipação do choque vai depender do ajustamento do modelo, evidenciado por um parâmetro de ajustamento $\alpha$.

Este trabalho utilizará o Teste de Johansen para detectar a existência de relações de cointegração entre as séries de interesse. Este teste procura definir o posto da matriz $\theta$ e, assim, estimar os vetores de cointegração contidos na matriz $\beta$ a partir de uma normalização destes vetores, o que permite identificar as matrizes $\alpha$ (ajustamento de curto prazo) e $\beta$ (cointegração de longo prazo). Para esta análise, é preciso determinar cuidadosamente o modelo de cointegração a ser testado e a ordem de defasagens dos componentes auto-regressivos a partir da combinação entre o menor valor do critério de informação escolhido e a ausência de autocorrelação dos resíduos.

As informações produzidas pelo teste de Johansen são utilizadas para especificar o Modelo de Vetores de Correção de Erros (VEC). O modelo VEC é um VAR convencional que utiliza o resíduo das séries cointegradas para melhor ajustar o sistema VAR no sentido de captar dinâmicas de curto e longo prazo entre as séries. A ideia básica é que o VAR com variáveis não estacionárias, mas diferenciadas, omite variáveis relevantes, na medida em que os resíduos da cointegração não são incluídos no modelo, o que pode resultar em estimativas viesadas dos parâmetros. Assim, o VEC corrige este problema ao incorporar os resíduos das séries cointegradas nas estimações para ligar o comportamento das variáveis no curto prazo com o seu valor no longo prazo (Gujarati, 2006; Bueno, 2008).

Para a estimação do modelo proposto neste trabalho, foram utilizados dados trimestrais para o período 2000-T1 a 2012-T4 obtidos junto às estatísticas do Banco Central do Brasil (BCB), Instituto Brasileiro de Geografia e Estatística (IBGE) e do banco de dados do Fundo Monetário Internacional (IFS, 2013), envolvendo as seguintes variáveis (em logaritmo natural):

Modelo $=$ AUT, TCR, INV, JUROS, IPI, ABERT, PROD, IPCOM

Onde:

AUT $=$ Produção física da indústria de veículos automotores (índice $2005=$ 100)

TCR $=$ Taxa de câmbio real efetiva - produtos manufaturados (índice $2005=$ 100)

INV = Taxa de investimento (Formação bruta de capital fixo/PIB) $(\%)$

JUROS = Taxa de juros Over-Selic (\% a.t.)

IPI = Arrecadação de IPI automóveis (Receita bruta de IPI automóveis/PIB) (índice $2005=100$ ) 
ABERT $=$ Grau de abertura comercial da economia ${ }^{3}(\%)$

PROD $=$ Produtividade do trabalho na indústria ${ }^{4}$ (índice $2005=100$ )

IPCOM = Preços de commodities (índice $2005=100$ )

Reescrevendo o modelo anterior na forma VEC, tem-se a seguinte equação:

$\Delta A U T_{t}=\Phi A U T_{t-1}+\sum_{t-1}^{p-1} \Lambda_{i} \Delta A U T_{t-i}+\delta^{\prime} d_{t}+e_{t}$

Em que:

$\mathrm{dt}=[1, \mathrm{t}]$ ' é um vetor com variáveis determinísticas (TCR, INV, JUROS, IPI, ABERT, PROD, IPCOM).

$\delta$ é uma matriz de coeficientes, cuja dimensão é compatível com dt.

$\mathrm{Na}$ evidência de desindustrialização setorial pela via da Doença Holandesa, espera-se que a taxa de câmbio real esteja positivamente associada com a produção física de automóveis, ao passo que os preços das commodities devem ter uma associação negativa com a produção destes bens. Neste contexto, de acordo com Bresser-Pereira (2009), a apreciação cambial e os preços favoráveis aos produtos primários seriam propícios a uma especialização da economia em bens ricos em recursos naturais, implicando menor direcionamento de recursos produtivos e estímulos menores para a atividade industrial. Sendo a indústria de transformação composta por vários ramos de atividades, incluindo a indústria automobilística, supõe-se que esta última poderia ter sido afetada negativamente por tal processo, reforçando os efeitos de uma desindustrialização no âmbito nacional.

De outro lado, espera-se que uma alta taxa de investimento, taxas de juros menores, impostos mais baixos, ganhos de produtividade do trabalho e maior grau de abertura comercial estejam relacionadas a um desempenho favorável do setor automobilístico no Brasil. Esta análise tem fundamento na teoria econômica keynesiana, em que políticas monetárias e fiscais expansionistas ajudam a estimular a produção industrial pela ampliação do investimento agregado, com efeitos multiplicadores sobre as demais atividades produtivas, impactando positivamente na demanda agregada e no produto agregado. Além disso, sendo a indústria automobilística dependente das importações de insumos e tecnologia, o

(3) O grau de abertura comercial da economia foi mensurado pela soma das exportações e das importações divididas pelo PIB brasileiro.

(4) A proxy para a produtividade do trabalho na indústria foi construído com base no PIB da indústria em geral dividido pelo número de pessoas ocupadas nas regiões metropolitanas brasileiras. 
maior grau de abertura comercial da economia também tende a favorecer a produção do setor.

\subsection{Resultados e discussão}

A análise de cointegração requer a utilização de séries não estacionárias, isto é, integradas de ordem 1. O diagnóstico da raiz unitária das séries utilizadas nas estimações foi baseado na aplicação dos Testes Augmented Dickey-Fuller (ADF) e Phillips-Perron (PP). A Tabela 6, a seguir, apresenta uma síntese dos resultados destes testes.

Tabela 6

Testes de Raiz Unitária

\begin{tabular}{l|c|c|c|c|c|c}
\hline & \multicolumn{3}{|c|}{ ADF } & \multicolumn{3}{c}{ PP } \\
\hline Séries & t-ADF & Lag & OI & t-PP & Bandwidth & OI \\
\hline Produção física automóveis (AUT) & $-8.67 *$ & 1 & I(1) & $-7.10^{*}$ & 20 & I(1) \\
Taxa câmbio real efetiva (TCR) & $-6.90^{*}$ & 1 & $\mathrm{I}(\mathrm{I})$ & $-5.25 *$ & 41 & $\mathrm{I}(\mathrm{I})$ \\
Taxa de investimento (INV) & $-3.94 *$ & 4 & $\mathrm{I}(1)$ & $-8.02^{*}$ & 51 & $\mathrm{I}(1)$ \\
Taxa de juros (JUROS) & $-4.81^{*}$ & 1 & $\mathrm{I}(1)$ & $-3.66^{*}$ & 10 & $\mathrm{I}(1)$ \\
Arrecadação IPI automóveis (IPI) & $-9.91^{*}$ & 0 & $\mathrm{I}(1)$ & $-10.35^{*}$ & 4 & $\mathrm{I}(1)$ \\
Grau de abertura (ABERT) & $-8.92^{*}$ & 1 & $\mathrm{I}(1)$ & $-11.92^{*}$ & 34 & $\mathrm{I}(1)$ \\
Produtividade (PROD) & $-2.34^{* *}$ & 3 & $\mathrm{I}(1)$ & $-8.51^{*}$ & 51 & $\mathrm{I}(1)$ \\
Preços de commodities (IPCOM) & $-5.90^{*}$ & 1 & $\mathrm{I}(1)$ & $-4.76^{*}$ & 12 & $\mathrm{I}(1)$ \\
\hline
\end{tabular}

* (**) indicam rejeição de $\mathrm{H}_{0}$ a $1 \%(5 \%)$ de significância

Valores críticos do ADF e PP: $1 \%$ (-2.61) e 5\% (-1.95)

OI indica a ordem de integração da série

Estimações sem constante e sem tendência

Fonte: Resultados do Eviews 7.

Dado que a hipótese nula dos testes ADF e PP se refere à existência de raiz unitária nas séries, os resultados indicaram a não rejeição da hipótese nula para todas as variáveis analisadas em nível. As variáveis se tornaram estacionárias quando tomadas em primeira diferença, portanto, são consideradas integradas de ordem 1. Assim, é possível realizar a análise de cointegração.

Em seguida, foi feita a escolha da defasagem do modelo de Vetores AutoRegressivos (VAR), cujos resultados estão expostos na Tabela 7. 
Tabela 7

Escolha das defasagens do VAR

\begin{tabular}{c|c|c|c|c}
\hline Defasagens & $\log \mathrm{L}$ & AIC & SC & HQ \\
\hline 1 & 545.6786 & -19.73661 & $-16.92980 *$ & -18.67591 \\
2 & 634.1153 & -20.75480 & -15.45307 & -18.75127 \\
3 & 725.0705 & -21.87794 & -14.08127 & -18.93156 \\
4 & 876.7406 & $-25.53086^{*}$ & -15.23925 & $-21.64165^{*}$ \\
\hline
\end{tabular}

* indica defasagem selecionada pelo critério de informação

AIC: Critério de informação de Akaike

SC: Critério de informação de Schwarz

HQ: Critério de informação de Hannan-Quinn

Fonte: Resultados do Eviews 7.

O modelo VAR foi estimado com quatro defasagens. A seleção do número de defasagens adequadas para o modelo normalmente é realizada com base no menor valor indicado pelos critérios de informação. Uma vez que houve divergência entre os diversos critérios de informação, foram realizados testes de diagnóstico de resíduos (Testes LM de autocorrelação), cujos resultados, mostrados na Tabela 8 , indicaram a necessidade de três defasagens para não rejeitar a hipótese de ausência de autocorrelação serial (com 5\% de significância estatística) na defasagem correspondente.

Tabela 8

Teste de Resíduos LM Autocorrelação Serial

\begin{tabular}{c|c|c}
\hline Defasagens & LM-Stat & Prob \\
\hline 1 & 115.5866 & 0.0001 \\
2 & 99.88204 & 0.0028 \\
3 & 74.55990 & 0.1724 \\
4 & 86.90544 & 0.0300 \\
\hline
\end{tabular}

$\mathrm{H}_{0}$ : Não há correlação serial na defasagem de ordem $\mathrm{h}$

Fonte: Resultados do Eviews 7.

Procedendo desta forma, partiu-se para a estimação do Teste de Johansen a fim de investigar a existência de relações de cointegração entre as séries e obter o número de vetores cointegrantes. Os resultados do Teste de Johansen são exibidos nas Tabelas 9 e 10.

Considerando o nível de $1 \%$ de significância estatística, verifica-se que as estatísticas do traço (Tabela 9) e do máximo autovalor (Tabela 10) indicaram a existência de pelo menos três vetores de cointegração entre as séries, sinalizando a existência de relações de longo prazo entre elas. 
Tabela 9

Estatística do Traço

\begin{tabular}{c|c|c|c|c}
\hline \multirow{2}{*}{$\begin{array}{c}\text { No. de Vetores de } \\
\text { Cointegração }\end{array}$} & \multirow{2}{*}{ Eigenvalue } & \multirow{2}{*}{ Traço } & \multicolumn{2}{|c}{ Valores Críticos } \\
\cline { 4 - 5 } & & & $5 \%$ & $1 \%$ \\
\hline Nenhum ** & 0.827887 & 302.9549 & 182.82 & 196.08 \\
Ao menos 1** & 0.758290 & 211.4554 & 146.76 & 158.49 \\
Ao menos 2** & 0.629211 & 137.6145 & 114.90 & 124.75 \\
Ao menos 3 & 0.465608 & 86.02406 & 87.31 & 96.58 \\
\hline
\end{tabular}

*(**) denota rejeição da hipótese nula ao nível de 5\% (1\%) de significância estatística Fonte: Resultados do Eviews 7.

Tabela 10

Estatística do Máximo Autovalor

\begin{tabular}{c|c|c|c|c}
\hline \multirow{2}{*}{$\begin{array}{c}\text { No. de Vetores de } \\
\text { Cointegração }\end{array}$} & \multirow{2}{*}{ Eigenvalue } & \multirow{2}{*}{$\begin{array}{c}\text { Máximo } \\
\text { Autovalor }\end{array}$} & \multicolumn{2}{|c}{ Valores Críticos } \\
\cline { 4 - 5 } & & Aut & $1 \%$ \\
\hline Nenhum ** & 0.827887 & 91.49953 & 55.50 & 62.46 \\
Ao menos 1** & 0.758290 & 73.84094 & 49.42 & 54.71 \\
Ao menos 2** & 0.629211 & 51.59041 & 43.97 & 49.51 \\
Ao menos 3 & 0.465608 & 32.58457 & 37.52 & 42.36 \\
\hline
\end{tabular}

*(**) denota rejeição da hipótese nula ao nível de 5\% (1\%) de significância estatística Fonte: Resultados do Eviews 7.

Com a informação produzida pelo Teste de Johansen, testou-se a correta especificação para a estimação do modelo VEC, por meio do software econométrico Eviews 7, sendo que o modelo selecionado pelo menor valor do critério de Schwarz foi a especificação com tendência linear nos dados, com intercepto e com tendência nos vetores de cointegração (modelo 4), conforme aponta a Tabela 11 a seguir.

Tabela 11

Critério de Schwarz por Rank (linhas) e Modelos (colunas)

\begin{tabular}{c|c|c|c|c|c}
\hline Especificação & 1 & 2 & 3 & 4 & 5 \\
\hline $\begin{array}{c}\text { Tendência nos } \\
\text { dados }\end{array}$ & Nenhuma & Nenhuma & Linear & Linear & Quadrática \\
\hline \multirow{2}{*}{ Rank } & $\begin{array}{c}\text { Sem } \\
\text { intercepto, } \\
\text { sem tendência }\end{array}$ & $\begin{array}{c}\text { Intercepto, } \\
\text { sem tendência }\end{array}$ & $\begin{array}{c}\text { Intercepto, } \\
\text { sem tendência }\end{array}$ & $\begin{array}{c}\text { Intercepto, } \\
\text { com tendência }\end{array}$ & $\begin{array}{c}\text { Intercepto, } \\
\text { com tendência }\end{array}$ \\
\hline 0 & -15.95552 & -15.95552 & -15.85008 & -15.85008 & -15.42486 \\
1 & -16.14067 & -16.14816 & -16.11405 & -16.31794 & -15.92117 \\
2 & -16.06786 & -16.14812 & -16.17879 & $-16.44620 *$ & -16.10521 \\
3 & -15.66651 & -15.74110 & -15.81876 & -16.14657 & -15.82938 \\
4 & -14.96849 & -15.01307 & -15.05120 & -15.48145 & -15.24005 \\
\hline
\end{tabular}

Intervalo de defasagens: 1 a 2

Fonte: Resultados do Eviews 7. 
A partir destes diagnósticos preliminares, partiu-se para a estimação do modelo VEC para captar as dinâmicas de ajustamento de longo prazo entre as variáveis, cujos resultados estão apresentados na Tabela 12.

As evidências obtidas sugerem que a taxa de câmbio real efetiva possui uma relação negativa com a produção física de automóveis no longo prazo, sendo tal resultado estatisticamente significante. Isso significa que a conjuntura de câmbio apreciado durante boa parte da década de 2000 não prejudicou o desempenho do setor automobilístico brasileiro, o que se justifica pelo fato de o setor ser um grande importador de insumos (principalmente autopeças) e tecnologia. Por conseguinte, em certa medida, a apreciação cambial favorece a atividade automobilística ao baratear os custos de produção ${ }^{5}$. Ademais, verificase que os preços das commodities estão positivamente associados com a produção de automóveis no longo prazo, embora, neste caso, os resultados não tenham sido estatisticamente significantes. Destarte, os elevados preços externos dos bens intensivos em recursos naturais não pareceram ser danosos aos resultados da indústria automobilística doméstica. Neste sentido, não se pode afirmar a existência de um processo de desindustrialização derivado da Doença Holandesa em curso neste ramo da atividade industrial no Brasil.

A taxa de investimento, o grau de abertura comercial e o indicador de produtividade do trabalho apresentam uma associação positiva com a produção física de automóveis no longo prazo, sendo que tais resultados são estatisticamente significantes e possuem magnitudes mais expressivas. Isto indica a importância da promoção de taxas de investimento mais sustentadas para expandir a capacidade produtiva; da ampliação do grau de abertura comercial da economia, visto que o setor automobilístico envolve tecnologia relativamente sofisticada e insumos que são importados; e da elevação do grau de qualificação da força de trabalho empregada para promover ganhos de produtividade e alavancar os resultados do referido setor.

A taxa de juros (Selic) e a arrecadação de impostos (IPI) se mostraram negativamente associadas com a produção física de automóveis no longo prazo, com resultados estatisticamente significantes. Nestes termos, tem-se que as altas taxas de juros da economia prejudicam os resultados do setor automobilístico, uma vez que dificultam a aquisição de recursos pelas empresas para financiar a expansão da capacidade produtiva, além de obstruir as vendas de automóveis para os consumidores ao encarecerem o crédito para a compra do produto, restringindo a demanda.

(5) Mas, por outro lado, cabe destacar que a substituição das autopeças nacionais pelas autopeças importadas enseja uma dificuldade no que diz respeito ao ramo de autopeças em se inserir competitivamente na produção. 
Tabela 12

Estimativas do Modelo de Vetores de Correção de Erros (VEC) para a Indústria Automobilística Brasileira

\begin{tabular}{|c|c|}
\hline & Equação de Cointegração 1 \\
\hline AUT(-1) & 1.000000 \\
\hline $\mathrm{TCR}(-1)$ & $\begin{array}{c}-0.322871 * \\
(0.08212)\end{array}$ \\
\hline $\operatorname{INV}(-1)$ & $\begin{array}{c}0.622485^{*} \\
(0.09178)\end{array}$ \\
\hline JUROS(-1) & $\begin{array}{c}-0.259542 * \\
(0.06302)\end{array}$ \\
\hline IPI(-1) & $\begin{array}{c}-0.031446 * \\
(0.01522)\end{array}$ \\
\hline $\operatorname{PROD}(-1)$ & $\begin{array}{c}2.330935^{*} \\
(0.20120)\end{array}$ \\
\hline ABERT(-1) & $\begin{array}{c}0.596279 * \\
(0.06302)\end{array}$ \\
\hline $\operatorname{IPCOM}(-1)$ & $\begin{array}{l}0.024667 \\
(0.20120)\end{array}$ \\
\hline TREND & $\begin{array}{c}0.017502 * \\
(0.00202)\end{array}$ \\
\hline $\mathrm{C}$ & 1.698082 \\
\hline
\end{tabular}

Desvio-padrão entre ( )

(*) coeficientes estatisticamente significantes ao nível de $1 \%$ Fonte: Resultados do Eviews 7

Finalmente, cabe destacar que as políticas fiscais contracionistas (aumento de impostos em relação ao PIB) também parecem comprometer os resultados obtidos pela indústria automobilística. Daí a importância dos incentivos fiscais (redução/isenção de IPI) para estimular o setor, mecanismo que foi utilizado pelo governo brasileiro no período pós-crise internacional recente para sustentar a demanda agregada. No entanto, a menor magnitude do impacto dessa variável, relativamente às demais, sugere a menor relevância dos impostos para explicar os resultados de longo prazo do setor automobilístico, dado o caráter mais temporário que caracteriza este tipo de instrumento. 


\section{Considerações finais}

A literatura econômica, com base em Kaldor, enfatiza a importância do setor industrial para a obtenção de taxas de crescimento econômico elevadas. Neste sentido, tem-se que o bom desempenho da atividade automobilística, em decorrência do peso deste setor na atividade produtiva e de seus efeitos multiplicadores sobre o produto e a renda, se apresenta como um elemento crucial para que a economia possa alavancar ou sustentar sua taxa de crescimento do produto nacional. Sob tal contexto, se verifica a preocupação do governo brasileiro em adotar algumas medidas paliativas no cenário de crise internacional recente (pós-2008) a fim de manter as vendas, os empregos e a renda no setor de veículos automotores para sustentar a demanda agregada.

A análise dos indicadores da indústria automobilística mostra a relevância desse setor para a economia brasileira, destacando a renda gerada, o número de empregos, o porte das empresas e os salários pagos no setor. Por isso, tal indústria tem merecido destaque na formulação e implementação de políticas públicas. Ademais, um dos objetivos do governo federal é a desconcentração de renda entre as regiões brasileiras. Nesse sentido, o Valor da Transformação Industrial indica que houve progressos, com regiões historicamente afastadas do centro industrial como as regiões Nordeste e Centro-Oeste ganhando participação. Porém, a região Sudeste continua concentrando a maior parte da renda gerada. Outro objetivo do governo federal é o fomento à indústria por meio da isenção/redução da alíquota do IPI. Tal objetivo obteve êxito ao evitar demissões em massa durante os anos de 2009 e 2012, quando houve renúncia fiscal. Nos demais anos, houve arrecadação crescente, com maior percentual de participação da indústria automobilística na arrecadação total de IPI a cada ano.

Este artigo procurou investigar os efeitos das variáveis cambial, fiscal, monetária e comercial sobre o desempenho da atividade automobilística brasileira no longo prazo, com base no período 2000-2012, por meio da análise de Cointegração (Teste de Johansen) e da estimação de Modelo de Vetores de Correção de Erros (VEC).

As evidências empíricas sugerem que uma taxa de câmbio menos competitiva (apreciada) e os altos preços das commodities não foram obstáculos para o desempenho da indústria brasileira produtora de veículos automotores no longo prazo. Neste sentido, pode-se dizer que uma possível realocação dos recursos produtivos causada pela conjuntura de câmbio apreciado e altos preços dos produtos primários para os setores intensivos em recursos naturais, que contam com vantagens de custos e maior rentabilidade, não pareceu ocorrer no âmbito da indústria automobilística. Desta forma, não é possível se afirmar a existência de um processo de desindustrialização pela via da Doença Holandesa no referido setor. 
Todavia, o cenário de políticas macroeconômicas vivenciado pela economia brasileira ao longo da década de 2000, envolvendo baixas taxas de investimento, altas taxas de juros e alto peso dos impostos na renda, poderá contribuir para deteriorar os resultados da atividade automobilística, ensejando alguma desindustrialização do setor no longo prazo. Também se percebe a relevância dos ganhos de produtividade da força de trabalho para estimular o desempenho da atividade automobilística e do maior grau de abertura comercial da economia, na medida em que a indústria de automóveis é bastante dependente de tecnologia e de insumos importados. Em adição, os incentivos fiscais utilizados pelo governo parecem estimular a produção física de automóveis, porém tal resultado se mostra relativamente menos robusto em comparação às demais variáveis analisadas, dado o caráter mais temporário de tais incentivos.

Nestes termos, cabe ressalvar que a hipótese de desindustrialização no Brasil não deve ser considerada um fenômeno homogêneo, uma vez que os vários setores da indústria de transformação podem ser afetados de maneira distinta pela condição cambial, pelos preços das commodities e pelo conjunto das variáveis macroeconômicas (taxa de investimento, taxa de juros, abertura comercial, produtividade, arrecadação fiscal, dentre outras). No caso em questão, as evidências apontam que a indústria automobilística brasileira parece ter sido mais afetada pelo contexto das políticas econômicas adotadas no país, conforme o conceito de desindustrialização para as economias latino-americanas derivado das políticas liberalizantes exposto por Palma (2005).

Em termos de lições econômicas, salienta-se a necessidade da retomada do papel da atividade industrial na promoção do crescimento econômico brasileiro. Para isso, as autoridades governamentais devem definir e implementar uma política industrial mais ativa, que permita uma reestruturação da indústria nacional em bases mais concretas, com a ampliação dos investimentos, fornecimento de infraestrutura adequada, promoção de custos de produção mais baixos, maior produtividade e qualificação dos trabalhadores, dentre outros. A partir desses alicerces, os setores tecnologicamente mais avançados conseguirão ser alavancados, e, em conjunto com a incorporação de valor aos produtos primários, o país poderá sustentar taxas de crescimento do produto mais elevadas no longo prazo.

\section{Referências bibliográficas}

BCB. Banco Central do Brasil. Economia e Finanças. Séries Temporais. Disponível em: http://www4.bcb.gov.br/?SERIESTEMP. Acesso em: mar. 2013.

BRESSER-PEREIRA, L. C. A doença holandesa. In: Globalização e competição: por que alguns países emergentes têm sucesso e outros não. Rio de Janeiro: Elsevier, 2009, cap. 5, p. 141-171. 
BRESSER-PEREIRA, L. C.; MARCONI, N. Existe doença holandesa no Brasil? In: FÓRUM DE ECONOMIA DA FUNDAÇÃO GETÚLIO VARGAS, 4, mar. 2008. Disponível em: http://www.bresserpereira.org.br/. Acesso em: out. 2008.

BUENO, R. D. L. S. Econometria de séries temporais. São Paulo: Cengage Learning, 2008.

CORDEN, W. M. Booming sector and Dutch disease economics: survey and consolidation. Oxford Economic Papers, v. 36, n. 3, p. 359-380, Nov. 1984.

; NEARY, J. P. Booming sector and de-industrialisation in a small open economy. Economic Journal, v. 92, n. 368, Dec. 1982.

CARVALHO, L.; KUPFER, D. A transição estrutural da indústria brasileira: da diversificação para a especialização. In: ENCONTRO NACIONAL DE ECONOMIA, 35. Anais... Recife: Anpec, 2007.

DALUM, B.; LAURSEN, K; VERSPAGEN, B. Does specialization matters for growth? Oct. $1996 . \quad$ Disponível em: http://www.druid.dk/laursen/papers/teis005.pdf. Acesso em: May 2008.

ENGLE, R.; GRANGER, C. W. J. Cointegration and error correction: representation, estimation, and testing. Econometrica, v. 55, n. 2, p. 251-276, 1987.

GUJARATI, D. N. Econometria básica. 4. ed. Rio de Janeiro: Elsevier, 2006.

HAUSMANN, R.; HWANG, J.; RODRIK, D. What you export matters. Cambridge, MA: National Bureau of Economic Research, Dec. 2005. (NBER Working Paper).

IBGE. Instituto Brasileiro de Geografia e Estatística. Indicadores. Pesquisa Industrial Mensal - Produção Física. Disponível em: http://www.sidra.ibge.gov.br/bda/acervo/acervo2.asp? $=\mathrm{c} \& \mathrm{p}=\mathrm{PZ} \& \mathrm{v}=28 \& \mathrm{z}=\mathrm{t} \&$ $\underline{\mathrm{o}=22}$. Acesso em: mar. 2013.

IBGE. Instituto Brasileiro de Geografia e Estatística. Indicadores. Pesquisa Industrial Anual. Disponível em: http://www.sidra.ibge.gov.br/bda/pesquisas/ pia/default.asp?o=23\&i=P. Acesso em: mar. 2013.

- Indicadores. Cadastro Central de Empresas. Disponível em: http://www.sidra.ibge.gov.br/bda/pesquisas/cempre/default.asp. Acesso em: mar. 2013.

IFS. International Financial Statistics Database. CD-ROM. Washington, DC: International Monetary Fund (IMF), Dec. 2013. 
IPEADATA. Instituto de Pesquisa Econômica Aplicada. Indicadores. Disponível em: http://www.ipeadata.gov.br/. Acesso em: mar. 2013.

KALDOR, N. Causes of the slow rate of economic growth of The United Kingdon. Cambridge University Press, 1966.

LAMONICA, M. T.; FEIJÓ, C. A. Crescimento e industrialização no Brasil: uma interpretação à luz das propostas de Kaldor. Revista de Economia Política, v. 31, n. 1 (121), p. 118-138, jan./mar. 2011.

LIBÂNIO, G. Quem tem medo da China? Análise e implicações para os principais estados brasileiros. Revista de Economia Contemporânea, Rio de Janeiro, v. 16, n. 2, p. 259-286, maio/ago. 2012.

NEGRI, J. A. de. O custo de bem-estar do regime automotivo brasileiro. Disponível em: http://ppe.ipea.gov.br/index.php/ppe/article/viewFile/187/121. Acesso em: jul. 2013.

OREIRO, J. L.; FEIJÓ, C. A. Desindustrialização: conceituação, causas, efeitos e o caso brasileiro. Revista de Economia Política, v. 30, n. 2, abr./jun. 2010.

OICA. Organisation Internacionale des Constructeures d'automobiles. Disponível em: http://www.oica.net/. Acesso em: mar. 2013.

PALMA, J. G. Quatro fontes de "desindustrialização" e um novo conceito de

"Doença Holandesa". Conferência Industrialização, Desindustrialização e Desenvolvimento. FIESP e IEDI. Ago. 2005. Disponível em: http://www.fiesp.com.br/. Acesso em: out. 2008.

RODRIK, D. What is so special about China's exports? Cambridge, MA: National Bureau of Economic Research, Jan. 2006. (NBER Working Paper Series, n. 11947).

ROWTHORN, R.; RAMASWANY, R. Growth, trade and deindustrialization. IMF Staff Papers, v. 46, n. 1, Mar. 1999.

SILVA, M. V. A indústria automobilística em Catalão/Goiás: da rede ao circuito espacial da produção da MMC Automotores do Brasil S.A. 2010. Tese (Doutorado em Geografia)-Universidade Federal de Uberlândia, Uberlândia, 2010.

STOCK, J.; WATSON, M. Vector autoregression. Journal of Economic Perspectives, v. 15, n. 4, Mar. 2001.

THIRLWALL, A. P. A natureza do crescimento econômico: um referencial alternativo para compreender o desempenho das nações. Brasília: Ipea, 2005. 